\section{ON THE TEACHING OF CLINICAL MEDICINE.}

\author{
By J. MACKENZIE, M.D., F.R.C.P., LL.D.
}

THE problems of medical education and of medical research at present engage the attention of the profession not only in this country but in many others as well. Two in teresting reports by Abraham Flexner-one on medical education in America and Canada, and the other on medical education in Europe-have been published by the Carnegie Foundation for the advancement of teaching. The Royal Commission on University Education in London has included medical education within the scope of its work, and has examined witnesses and drawn up recommendations, and has appointed a Departmental Committee to give effect to the recommendations.

In the two reports by Flexner and in the evidence of the medical witnesses examined by the London University Commission there is a very large amount of information and many suggestions from teachers of medicine drawn from different parts of the globe, of experts in various sciences, and of education authorities, practical and doctrinaire. It might be anticipated that the information obtained in this way would provide material from which the best plan of medical education could be evclved Nevertheless, a critical examination of the evidence given and of the conclusions drawn from such evidence, in so far as the evidence relates to clinical medicine, reveals defects of such a serious nature that any scheme elaborated on such evidence and suggestions alone will do little to advance the cause of clinical medicine, and may even retard its progress for an indefinite number of years. The reason for this prediction is, that points which are essential to a medical education and to the progress of clinical medicine have been realized neither by the witnesses nor by the Commission.

\section{Clinical Medicine as a Scrence.}

In order to understand why it is that clinical medicine fails to advance, or advances so slowly, it is necessary, in the first place, to consider the features peculiar to clinical medicine as a science.

All sciences have evolved gradually from the stage when the term "science" could not be applied to them. In the term "science" is included the uccurate observation and the verification of all statements, and the elimination of all statements based only upon tradition and not verified by actual observation. While most sciences, as chemistry, mathematics, and astronomy, have to a great extent passed out of the traditional stage, medicine has not yet begun to emerge from this stage, and it is still so encumbered by tradition that it hardly deserves the name of a science.

While the principles of investigation in all sciences are identical, the methods by which the sciences are pursued are naturally extremely varied, according to the phenomena that have to be investigated. Thus the science of geology requires different methods for its pursuit from that of chemistry. If, however, the chemist imposed his methods upon the geologist and pursuaded him to devote his time to laboratory work alone, then no doubt the geologist would acquire some new facts as to the chemical composition of rocks, but if he neglected the means of ascertaining by actual observation the distribution of the strata he would acquire an extremely limited knowledge of the science of geology. If, moreover, a professor of geology was to be selected for teaching purposes because he had spent his whole time in the laboratory and never studied the subject by investigation in the country, the pupils of such a teacher would never be adequately instructed in the subject, and the science would cease to be progressive or make tardy advance only in less important lines.

This illustration applies to clinical methods. The pursuit of this subject as a science has been diverted from its natural course, and it has endeavoured to advance by imitating the methods of other sciences, and not by developing its own methods. The clinical laboratory and the wards of the hospital represent the chemical laboratories in the above illustration, and the concentration of effort on these limited fields has so restricted the progress of medicine, and the opportunities for its study, that the cry has gone up in all quarters of the inadequate advance of clinical medicine. Before any real advance can be made the methods peculiar to clinical medicine must be adopted, and the field of observation must extend far beyond the hospitals and laboratories. The truth of this proposition will be appreciated as I develop the subject.

\section{How Disease is Presented to the Medical} Profession.

To understand how medicine should be advanced it is necessary that we should appreciate how its problems present themselves to the medical profession.

The diagnosis of any disease depends upon the perception of the signs and symptoms which it creates.

The signs are of two kinds, those of which the patient is conscious, which may be summed up as an absence of well-being-subjective symptoms-and those symptoms where there is some physical sign of disease-objective symptoms.

In the early stages of disease the symptoms are nearly always limited to the first of these kinds - the patient's consciousness of there being something amiss. If it is due to some affection of an organ, then the function of that organ is disturbed, and as health may be considered as the harmonious action of the various organs, so ill. health is the disturbance of that harmony, and of this dis. harmony the patient becomes conscious. If the individual is invaded by some toxic influence, microbic or chemical, then this invasion is again first shown by the patient's consciousness.

It follows, then, that before any physical sign is per. ceptible the individual's sensations give warning of the presence of a disease process, and a physical sign may be taken as an evidence that the disease process has advanced so far as to cause a change in the structure of an organ, on has disturbed the function of that organ very markedly, as in altered action of the heart.

Recognizing, then, that the early stages of the disease are chiefly made manifest by subjective symptoms, and the advanced stages have in addition physical signs more or less marked, it will be well to see what opportunities the profession have of detecting disease at its different stages:

It will be convenient for the purpose in hand to contrast this subject from the standpoint of disease as it presents itself in the hospitals and in general practice.

First, then, in regard to the hospital patients. It may be said that, generally, patients do not go to hospitals until the disease has adranced so far as to cause in. capacity for work, or when it has become fairly well established. So frequent is a feeling of ill-health temporary and transient, that many people in the earlie stages of disease look upon the symptoms as being due to a transient complaint, and continue their work. It is only when the illness persists that they seek hospital advice. Many may come when the disease is so slightly advanced that there are no physical signs, and these patients, unless manifestly ill or in distress, are treated by the junior physicians in the hospital.*

If physical signs are present, then they are given more attention, and if the physical sign is a rare one, or the patients be very ill, they are then admitted into the wards of the hospital, where they are under the care of the senior and more experienced physicians. Here they may remain for a few weeks or months, and careful examina tions are repeatedly made by means of the resources of a well-equipped hospital. If they drift and die there follows a careful post-mortem examination.

The general practitioner has the opportunity of seeing patients under very different circumstances. It must be remembered that the vast proportion of the sick passes into his hands, and that the vast majority of people never go near a hospital even when they are dangerously ill. The family doctor is often consulted for the most trivial ailments,

* I may here remark that I was recently for three years a physician of the out-patient department of a consumption hospital, and during the whole of that timeI never saw one patient in the early and curable stage. In fact, the last place for discerning the early and curable stage of consumption is in the wards or out-patient department of a consumption hospital, for the simple reason that patients never go to the invasion hes taken place. 
and as these trivial ailments are frequently the first sign of a long protracted disease he las the opportunity of seeing many illnesses at a stage earlier than the hospital physician. As these patients are always under his observation he has the further opportunity of seeing the signs of disease progress until they show definite physical signs, and after this he can watch impaired individuals for years until they die.

From this brief statement it will be seen that as far as opportunity goes the general practitioner sees disease earlier and can watch its progress better than the hospital physician.

Hitherto, unfortunately, these advantages which the general practioner has have never been properly made use of. The investigation into disease has been left almost entirely in the hands or under the direction of the hospital physician, whose opportunities do not permit him to see the earlier stages, except as they appear in the out-patient department. He has no real opportunity of watching the progress of a disease over an extended period, for in hospital the duration of study of a patient is comparatively limited, and it is not possible for the physician to follow and watch the changes that gradually ensue as the disease progresses.

\section{Reasons for the Tardy Advance made by Clinical} Medicine.

It is worth while to consider more fully how clinical medicine has failed to use the opportunities for the treat. ment and detection of disease in hospitals - the field invariably assumed to be the best for research.

It is an axiom that the earlier a disease is recognized the more susceptible it is to treatment, and next to preventing disease, the most imperative duty of the physician is to recognize it at its very earliest stage. If we review our knowledge of the various diseases, we must recognize that we are profoundly ignorant of the earliest stages of almost all chronic diseases. The early history of consump. tion, of cancer, of rheumatoid arthritis, of gastric ulcer, of appendicitis, of arterio-sclerosis, is a complete blank. It is true that here and there some will declare that they know these stages as early as it is humanly possible to do so, but a critical examination of their evidences will show how little basis there is for the assertion, and if the manner in which disease is investigated be considered, it will be found that, in the nature of things, it has been physically impossible for these early stages to have been discovered. Consider how disease is investigated in the hospitals. In the wards we have the senior and more experienced physicians, helped in some cases by a number of assistants trained in particular departments, so that all available means of diagnosis and treatinent are brought to the consideration of the cases. The majority of the cases have got some well-marked physical sign, and these signs are studied from every point of view. As these signs indicate some damaged tissues, the disease has passed beyond the stage of simple functional disturbance, and has caused some alteration or destruction of normal tissue. This stage in chronic disease is for the most part incurable in the sense that the normal structure cannot be restored, and all that can be hoped for is to stay the progress of the disease. In many cases this is not possible, and the patient dies, and then the opportunity for the further study of the disease is obtained by the post-mortem examination.

It is in the wards that the greatest amount of teaching is carried on, and there also that the ardent student seeks to pursue the investigation of disease. Under such conditions disease is detected by physical signs. The teacher demonstrates the disease by the physical signs. Most of the methods are constructed so as to discover physical signs, and, consequently, physical signs occupy a dominant position in the minds of teachers, assistants, and students.

The other field for observation in hospitals is the outpatient department. Here disease presents itself in a more varied aspect. Patients come here complaining of sensations which tell them there is something wrong. The patients are seen by junior physicians who are begin. ning their study of disease, who have been trained in the wards, and who are adepts in the detection of physical signs. They have to select cases that are suitable for the wards, and in the main are guided in this selection by the presence of physical signs. Where there is teaching done in the out-patient department these cases with physical signs are selected, for the junior but imitates the senior in the wards. Those patients with no physical signs, and who show no signs of grave illness, are either dismissed with a perfunctory examination, or handed over to a house-physician.

The existence of such conditions shows the topsy-turvy state of clinical medicine. The early and curable stage of disease is practically neglected, and all the energy of the more experienced physician with his numerous assistants directed to the study of disease after it has passed from the curable stage. It is notorious that the early stages of disease are the most difficult to recognize, the signs being so slight and elusive, while it is comparatively easy to recognize disease after it has advanced so far as to pro. duce physical signs. Yet the easiest and least useful part of investigation is reserved for the experienced physician and all his assistants, while the more difficult and most necessary part of the work is handed over to the least experienced, or even the inexperienced physician.

Or put the mattor in another way. The patient with a disease in the early and curable stage receives the least attention, and is actually not considered a fit subject for thorough examination and treatment till his disease has become firmly established and for the most part incurable.

What has been said of the neglect of the early and curable stage of disease can also be said of the prognosis of disease. It is no doubt true that in many cases of a rapidly progressive nature, or in the later stage of some chronic disease, the prognoses have been accurately enough worked out. But it is no exaggeration to say that the methods by which a prognosis can be arrived at have never yet been appreciated, because teachers have recognized neither their limitations nor their lack of opportunity.

Hospital patients are under observation only for brief intervals, and though hospital physicians may make attempts to watch patients. yet the circumstances of the case prevent them doing this in a competent manner. Take a case of rheumatic fever and the results that follow -a damaged heart. The hospital physician sees the acute attack and may detect an endocarditis. The patient leaves the hospital with a more or less damaged heart. For a number of years the heart maintains an efficient circulation. By-and-by heart failure begins to appear, and the hospital physician may have him under observation during a few attacks of heart failure until he dies, when he may get a post-nortem examination. During the patient's life, dating from the period of his rheumatic attack, changes of a slowly progressive nature have been going on, modifying the heart's action in a variety of ways. These changes are subtle and difficult to detect, but they have an influence on the heart's efficiency. The hospital physician has never the chance of detecting these subtle changes, so that when the heart fails to such an extent that the patient seeks his advice, he is unable to appreciate the factors that have brought this failure about. The result is that the knowledge of heart failure is based on the conclusions drawn from very imperfect data, and as a consequence the prognosis of heart failure is often a mere matter of guesswork, while the mechanism by which heart failure is brought about has never been detected. What is true of heart affections--for the truth of the above statements can be demonstrated-is no doubt true of every chronic affection.

The line of teaching and of investigation which has been pursued of late years accounts for the diversion of clinical medicine into the wrong channels. The use of methods from other branches of science has drawn attention away from the methods that are peculiar to clinical medicine. So long as these methods are neglected very little progress can be made. I do not deny that special methods have brought to light valuable aids to diagnosis, but much of this energy is misdirected, as shown by the relative amount of work in the hospital wards compared with that in the out-patient department, while the obsession for those methods to which the term "scientific" is commonly limited has diverted attention from the true scientific methods of clinical medicine.

The Training of the Teacher.

In order to appreciate the reason why medicine has been so badly taught, and has advanced so slowly, it is necessary to consider the qualifications of those who are 
responsible for teaching and research. For this purpose the manner in which the teacher is trained will throw light upon the matter.

The student, when he enters upon the study of clinical medicine, devotes most of his time to the wards. Here he is taught the physical signs of disease, and here he has the opportunity of seeing disease in its advanced stages, and here he can study disease by the aid of accessory sciences, as chemistry, bacteriology, histology, radiology, and so forth. He may watch the disease advance until the patient dies, and then he has the further opportunity of studying post mortem all the changes which have come about by the gradual extension of the disease, and so gets a knowledge of the last stage of disease. In this manner he becomes very familiar with well-established illnesses, and particularly when they are beyond the hope of cure.

The student who hopes to become a teacher after he is qualified goes through a series of minor appointments, and in waiting for a post may employ himself in diverse ways. He may work in some laboratory either at home or abroad, and spend much misdirected energy in what is called " research," which almost invariably means working out some problem of little importance. $\mathrm{He}$ may seek minor appointments at some other hospital; but one thing he must not do if he wants to get a post as teacher of clinical medicine-he must not carry out the work which would be essential to qualify him to be an efficient teacher. Tradition dictates that if he wants to get on to the staff of a hospital, and therefore to teach students who become general practitioners, he must be careful to ayoid acquiring a knowledge of disease as it presents itself to a general practitioner. The budding teacher must limit himself to a knowledge of how to treat disease with all the accessories of a hospital. He must not see disease in its early stages, and he must not learn to treat patients at their own homes where the opportunities are limited, and he must not acquaint himself otherwise with the duties of a general practitioner, because he knows that to become a general practitioner would handicap him in obtaining a post at a teaching school.

To such an extent does this absurd practice prevail that some young aspirants to hospital appointments make a point of declining to undertake the treatment of a private patient in order that they may claim to belong to the class of practitioners known as consultants, utterly oblivious of the fact that they are thus depriving themselves of the only opportunity they will ever have of acquiring a full knowledge of the progress of disease.

When a man is appointed to the staff of a teaching hospital, among his duties is the giving of instruction in physical diagnosis. His conception of what constitutes physical diagnosis is limited to the few signs he was accustomed to see demonstrated in the wards when he was a student. From actual experience he has no know. ledge of the significance or the meaning of the signs which he teaches, and what little information he has to give is second-hand, which has come to him by the same process as that which he gives to the students under his care. At the outset, then, he becomes the vehicle for passing on a tradition, and if there is anything that injures a man's intellectual activity it is to become the mouthpiece of tradition-teaching by faith and not by reason. The students at this time are at the most receptive period of their career, and on the clean slate of their minds the half-trained junior stamps his beliefs.

This junior teacher gets most of his practice in the outpatient department, and as his previous training has been in the hospital wards or in a laboratory, he does not know how to set about detecting the subtle and more elusive signs of disease, but concentrates his attention in the search of physical signs, in the finding of which practically overy young physician prides himself. He knows that the patients that are wanted for his chief in the wards must have physical signs, and those who show none are speedily disposed of.

In course of time the out-patient or assistant physician gets what is considered promotion, and he passes up to the serener atmosphere of the wards, where he may have assistants and laboratories, and where he firmly believes he is about to enter on a career of scientific investigation.

Consider what his opportanities have been. In his lectures he deals with every disease in a systematic form -etiology, symptomatology, prognosis, and treatment.
What opportunity has he had in the whole course of his career in studying the etiology of disease? As already shown, he has shunned the possibility of seeing cases in the very early stage in general practice. When he had an opportunity in the out-patient department, the early cases without physical signs received little or no attention. In the wards, where he may have spent the greater part of his life, he may see advanced incurable cases. As a consultant patients are never brought to him until their disease is well established.

What opportunities has he ever had of watching the progress of disease? In the hospital he may have a patient under his care for a few weeks, or, if he is dying, for a few months. As a consultant he sees a patient once or occasionally a few times. Unless it is in the later stages of disease when the patient is steadily progressing to death he has never had the opportunity of watching the course of a chronic disease.

The Attitude of Teachers towards Research.

It may be said that the object of a scientific education is to instruct students in accurate methods of investigation, and laboratory methods train the mind to accurate observation. But it is here that the exponents of what is called scientific medicine go wrong. Instead of recognizing that clinical medicine is a science apart, with methods of its own, they simply imitate other sciences. Apart from the recognized methods of physical examination which have been in use for several generations, the whole tendency of recent teaching has been to seek assistance from methods which are useful in other sciences, such as by the microscope, $x$ rays, and other mechanical means. No doubt all these have their places, and are of service, but they are not of the essence of clinical medicine. Disease gives rise to many symptoms of a nature that cannot be brought to light by mechanical means, and they are often extremely difficult to detect, and require a great deal of further observation to explain. Except for the more easily recognized symptomatology, the tendency has been to ignore those that did not come within a certain limited category. I could illustrate this in many ways, and some illustrations will be given when I deal with my personal experiences. Here I would direct attention to the field of the greatest importance, which amply justifies my criticism of the attitude of the teaching profession towards scientific medicine.

The backward state of medical education is well illus trated by the attitude of the profession to methods of treatment. The total absence of anything like science in this department is shown by the great variety of methods of treating any one disease, and the extraordinary recommendations that are published by different teachers. This but demonstrates that clinical medicine has not yet emerged from a condition of servitude to tradition and even to superstition. It is not so many years ago that a schism arose because some members of the profession were led by a fantastic theory to adopt an unusual attitude to the supposed action of remedies. The orthodox views of the profession with regard to remedies were based on little better than tradition. In science there can be nothing of the nature of a schism, and it is only in matters of belief and faith that a schism can arise. If the authorities in the past had had but the faintest perception of the nature of their beliefs and how far many of these were from having a basis of truth, no schism could have been possible. But the same curious unreasoning belief in the efficacy of remedies is as rampant to-day as ever, and this is entirely the outcome of the clinical teaching, for the faith in ineffective remedies, though given by such scientific methods as the hypodermic syringe, is as simple and as trusting as the belief in charms and incantations of a bygcne age.

Let anyone seriously investigate the manner in which therapeutics are taught and exemplified even in those model scientific wards where the chief physician is assisted by some ten or dozen skilled scientific assistants. The observing student will find drugs administered, and not the slightest attempt made to see if they have the action that the physician supposed them to have. If he cares to investigate the matter more closely and tries to find the grounds on which the physician prescribes the drug, it will be found that it is prescribed because some authority has observed that it has a certain effect. If he inquires 
further he will find out that in the majority of cases the evidence for its action is based on such flimsy grounds that there is no justification for its use. Even if it has some demonstrable action its effects in other ways have never been sought for.

Now, in the action of remedies there is always a variety of symptoms provoked. Some more obtrusive action may be detected, and that is the effect that is taught and demonstrated. The other less obtrusive signs are ignored. Take, for instance, the action of an aperient. It is prescribed and the nurse enters on the chart the number of times the bowels have been moved, and that is all, except that the bacteriological and chemical assistant may make an analysis of the stool. But the whole series of subjective phenomena are never investigated-such as the feeling of nausea, when it occurs or when its ceases; the sensation of pain, the time and place of its starting, the regions into which it spreads, the occasion of its cessation. Other changes may occur, as tonic contraction of the muscles of the abdominal wall, and altered sensibility in the skin and muscles in certain well-defined regions, but these pass unrecognized.

It may be said that these are unnecessary facts, which it would be a waste of time to analyse. There is a certain amount of truth in this statement, for it requires much discrimination to differentiate between the essential and non-essential. But in the case I have taken for illustration, if the student had been taught to find out all about the sensations of nausea, and of pain, and how to appreciate the associated phenomena, he would have derived a knowledge of the very first importance in a neglected field of clinical medicine. In addition, he would have the opportunity of seeing symptoms arise and disappear. The action of the digestive tube gives rise to those symptoms, and the portion of the intestine that passes into strong peristalsis gives rise to pain in a definite area. In practice the physician is constantly coming across cases of affection of the intestine, in which the pain and associated phenomena are so instructive that it is possible to locate the site of the trouble with great precision. Yet at the present day all these instructive phenomena are ignored or misunderstood by the great bulk of teachers of clinical medicine, and such simple means of observing them are never taken advantage of.

While I have mentioned an aperient as an illustration, I might have chosen almost any drug in the pharmacopoeia, and I could say without fear of contradiction that not one single drug has been carefully studied so as to understand its full effects on the human system, effects that could be easily recognized had a systematic examination been carried out when it was administered in the hospital wards. Even if we take drugs with a deservedly high reputation for their beneficial effects, as those of the digitalis group of remedies, we find the teaching profession has never accurately observed them, so that to-day the principle on which the drugs are administered is not scientific, but rule of thumb, and based on imperfect observations. The reason for this is partly due to the fact that the profession has never understood the meaning of the phenomena which the drug produced.

In referring thus to treatment, I use the illustration not only to show how the opportunities for studying clinical phenomena and the action of remedies are neglected, but for another purpose, namely, to show how the attitude of the physician to this subject has a most baneful effect upon the students' minds. In the wards and in the laboratories he is taught to examine a limited number of phenomena, and he is taught laboratory methods with pedantic precision. It may be the student acquires a considerable amount of dexterity in these methods, and there is in the teacher that sense of satisfaction that the students are receiving a scientific education. When, however, the teacher after all the elaborate examinations comes to treat his patient, the student sees some drug given to the patient, because of some supposed effect, and then little attention is paid to what the result may be. $\mathrm{He}$ is never taught how to investigate the action of the simplest remedies. When the student passes into general practice he finds the call for these elaborate scientific methods so infrequent that he gradually ceases to use them. On the other hand, to every patient he has to apply methods of treatment. His teaching in this repect has been slipshod in the extreme, and he has no knowledge how to investigate the action of the reme. dies he prescribes. He gives remedies because of faith and not of reason, and as he was never shown how to watcl the effects of remedies, he readily becomes the prey of the advertising chemist or other purveyors of specific treat. ments, who describe their wares with a gloss of scientific jargon which misleads the untutored practitioner. So notwithstanding all the scientific methods, the deplorable state that treatment is in at the present day is due to the slovenly methods employed by those who have failed to grasp the true nature of the science of clinical medicine.

\section{Personal Experiences.}

Lest it might be considered that the position of strong hostility to the present day methods that I have adopted is merely the expression of opinion not based on sufficient grounds, I am constrained to refer to my own personal experiences in order to illustrate the experiences that befall the practitioner. However much my views may be scouted by the teachers, I know they will appeal to the vast majority of practitioners who have suffered from inefficient teaching. I could have illustrated my remarks from other sources, but for the purpose in hand my own experience represents that of the great bulk of general practitioners, and though my attempts to remedy my deficient education may not have been very successful, yet they may serve to convey a knowledgc of where the teaching of clinical medicine fails These experiences refer back to medical education as given thirty years ago, and it will no doubt be contended that enormous advances in education have been made since then. I fully recognize that certain depart. ments, as bacteriology and physiology, have made enormous advances, yet the really scientific teaching of clinical medicine has made little or no advance-in some respects it has retrograded in the sense that the general practitioner is less fitted by his training for the duties of his profession now than he was then. The reason for this is that the teacher of thirty or forty year's ago had been a general practitioner, and knew by experience the kind of life the students who would enter general practice would lead, and the aspect that disease would present. Nowadays the teacher is usually innocent of this experience.

On entering general practice I was under the impression that the knowledge of disease was so nearly complete that there was absolutely nothing to be done but to apply that knowledge to my patients. I speedily found that I, at all events, was extremely deficient in my knowledge, for I was continually puzzled by the fact that the majority of my patients presented features widely different from what $I$ had seen in my hospital training. I put it down to my own fault in not having acquired the knowledge, and turned to textbooks and visited hospitals in order to improve myself, and took my patients to consultants. Still I made little progress, and after several years it gradually dawned on me that the field of clinical medicine had not, perhaps, been so fully explored as I had thought, and I resolved I weuld begin to observe for myself, and take note of every sign or symptom that might appear. I soon found that I was very ignorant of a great many signs and symptoms, some of them very obtrusive, and when I turned to my textbooks I found a complete silence on the subject, or a description so little in accord with the facts that it was evident that the authorities did not understand the subject any more than I did. I therefore took courage and laid down a rule that $I$ would not slur over any sign or symptom, but carefully note its presence, try to understand its mechanism and its relation to other phenomena, and to see what bearing it had on the patient's future. Carrying out this idea, I soon came across such a bewildering variety of strange phenomena that it was in vain to attempt to follow them all, so I selected some of the more conspicuous and studied them. But I had scarcely set out on this inquiry when I found that I had to re-educate myself in methods and instruct myself in some of the more simple facts in physiology. I found I had never properly understood the very first thing met with in examining a patient, that is, the significance of the statements made by the patient in describing his complaint. I found that in failing to appreciate the significance of the patient's statements, it was not so much a question of the patient's incoherence as of my own ignorance in understanding the condition that gave rise to 
the sensations. The majority of patients complain because of something that tells them they are not in perfect health. The patient himself cannot very well explain, his recollections are often vague and eren misleading. If, however, the patients are carcfully interrogated by getting them to tell of the most trifling circumstances and by cntering fully into their feelings, a great deal of light can be thrown upon their complaints. Thus, for instance, the patient would describe attacks of exhaustion and attacks of weakness and of giddiness, and he might vaguely call them heart attacks. A physical examination miglit reveal no abnormality, and I would be at a loss to account for the sensations. But as I acquired a better linowledge of the heart's abnormal action, I enclearoured to recognize at the same time the sensations that accompanied it. In course of time $I$ acquired a knowledge that enabled me to recognize from the patient's statements the nature of some of the complaints that hitherto I had put aside as of little importance.

Now what is true of the heart is true of the sensations produced by other organs, and while I am still ignorant of many sensations produced by the disarrangement of other organs. nevertheless I have found the recapitulation of the patient's sensations the most helpful nart in the examination, and have recognized how difficult it is to interpret these sensations and to correlate them with the altered function.

I must confess there are a large number of phenomena the significance of which $I$ have failed fully to comprehend. This applies particularly to those which appear in the very early stage of chronic complaints, but I have gained sufficient insight into the matter to permit me to state mest emphatically that diseases do give evidence capable of recognition long before the present day methods can detect them. Thus, if we take consumption or tuberculons riseases generally, in the course of $m y$ obserrations I found patients complaining raguely of symptoms--varying from time to time. The most careful cxamination revealed no physical sign, save at times an increased rate of the pulse beat. Such cases would go on for years until a cough or expectoration would indicate some definite disease of the lung, or the pointing of an abscess would indicate the seat of some tuberculous infection. The discrimination of these cases is still beyond me, because I liad not realized what was to happen, and had not taken sufficient care to note all the concurrent phenomena. But of this I am certain, that definite symptoms do exist, and if consumption is ever to be recognized and cured, the general practitioner is the only individual who has the opportunity of detecting it in the curable stage.

Besides these obscure sensations, difficult to icscribe, I found that even the most clamant of srmptoms-- painhad never really received the attention from clinicians which it deserved. It so happened in wy practice that I saw a large number of people suffering from aftections of the digestive organs, and my first study was centred on the pain produced by the abdominal organs. Br paying careful attention to the pain, the site of its origin, the manner of its radiation, and the circumstances that pro. voled it, I gradually saw that in this symptom far more information was to be obtained than I had erer expected. But it required great care to get out the facts, and re. peatedly the patient's memory was so much at fault that I was baffled. When the pain tended to recur I got him care. fully to note all the circumstances. Morcorer, as a general practitiouer I was frequently summoned to see a patient in great pain, and had the opportunity of questioning the patient while actually suffering. From facts derired in this manner I was gradually able to see that there was a principle underlving the production of pain which, if ascertained, would be of cnormous advantage. Although I gradually acquired a better knowledge, and was able to adopt a hypothesis to explain the symptoms, it took me a long time to get proofs. Thus the first patient on whom I was able to demonstrate the relation of a gastric ulcer to the pain area I liad watched and studied for ten years. But by pursuing this line of obserration in cases of gastric ulcer. and with cases of obstruction in the bowels, and noting the pain as it shifted with diarrhoea, 1 was able to show that there was an intimate ronnexion between the different parts of the bowel and definite regions in the abdominal wall, so that in certain cases of obstruction, for instance, I would be able to indicate within certain limits the part of the bowcl that was obstructed. This line of observation also enabled me to differentiate the pain due to the digestive tract from the pain due to the other abdominal viscera with more precision than had hitherto been done.

In pursuing this line of observation other phenomena were detected associated with pain. Thus, carly in these investigations my attention was arrested by serere cutaneous hyperalgesia in a patient with gall-stone colic. This led me to search for altered sensations, and I found out that hyperalgesia was not an infrequent symptom. But the question arose, In what tissues was this altered sensa tion present? It is a remarkable fact that at the time I was studying the question there was no linowledge of the sensibiiity of the different tissues of the human body. It was necessary, then, to inquire into this matter, and I undertook a long series of observations whenerer occasion permitted, to test the sensibility of cut wounds, the lining of cavities, and their contents. By this means I was able to test the reaction to simple stimuli of such organs and tissues as the lungs and pleura, the peritoneum, bowel, liver, kidneys, ete., and I found them actually insensitivo to pressure, pinching, and cutting.

Other phenomena which I had to investigate presented themselres, such as the reflexes associated with dis. turbance of othicr organs. These reflexes not only affected the muscles of the abdominal wall in a peculiai manner, but also affected the activity of other organs sometimes remote from the original seat of trouble. Of these reflexes, that affecting the contraction of the muscles wall of the abdomen presented most instructive features, especially the curious manner in which limited portions of the muscle would remain contracted. It was almost impossible to differentiate these small hard contractions from tumour's in the abdominal cavity, and I have repeatedly seen them mistaken for tumours by experienced physicians and surgeons and the abdomen operated to remove them, when no tumour or swelling was found.

My purpose in mentioning these observations here is not to state my observations are completed or even accurate, but to call attention to striking clinical phenomena that are to a great extent igncred or misunderstood, and to state that I liave repeatedly found these phenomena present in cases which after a long period showed moro definite signs of cliscase, and that therefore this is one of a class of phenomena where we get cridence of a stage in disease earlier than has hitherto been recognized or realized.

I do not doubt that many physicians and surgeons ivill ask, But what bearing has this upon clinical medicine or surgery? With such questions I am quite familiar, and it is just an additional evidence showing how teachers in these subjects fail to recıgnize what is essential in clinical diagnosis. How often do we see surgeons and physicians diagnosing a tender liver, a tender gall bladder, a tender spleen, a tender colon! How do they demonstrate their diagnosis? By pushing their finger into the abdomen in the regions they imagine these organs to occupy. What are they doing? They are pressing on layers of very sensitive structures, and on other structures which aro completely insensitive to such stimulation, and describing the pain, not as caused by the sensitive structures, but as caused by the insensitive. Even in such a common complaint as appendicitis the nature and the meaning of the most striking phenomena present have never been understood, and, so far, I have come across no description of what structures are tender in the most common sign of all--McBurney's point.

While pursuing my researches into the nature of the phenomena, I always kept before me the bearing they might have upon the patient's future. As far as I could I kept the patient under observation, and noted what changes took place as years went past. To do this I kept in touch with the patients, not only talking the opportunity that illness afto 0 ded, but by visiting them, and getting them to call on me at frequent intervals. By this means I was able to see the prognostic significance of some symptoms.

As an illustration, take the irregular action of the heart. At the time I began these investigations the preliminary step of differentiating one form of irregularity from another had not been taken, so that I had to spend a great deal of time taking this step. As these irregularities were recorded graphically, the records remained recognizable, 
so that $I$ could always turn to them in after-years, thongh at the time I might not understand their nature by comparing these with the results of animal experiments $I$ and other's engaged in the work were able to recognize the nechanism of their protuction. In this way I obtained not only a knowlerlge of certain forms of irregularity, but also, as year's went on, the prognostic significance of some of them. There is one form of the heart's irregularity that is of great frequence, occurring in people of all ages, which is usually recognized by the tcrm "intermittent pulse," but which is really duo to a premature contraction of the ventricle, the beat usually being so small that it is not perceived by the finger on the radial artery. This was one of the forms that I recognized at the very outset of my observations, and, fincling it of great frequency, I collected observations from a great number of people. In the course of a few years I hac obtained records of its presence in several thousands of people, so that I was able to get the age incidence of its occurrence. As I could not follow all the cases, I liept in contact with a great number of them, and kept records of how the heart responded to such incidents as pregnancy and labour, and such illnesses as pneumonia. Peopls employed in severe bodily work frequently showed it, and I lept in contact with a number of these. Some of them I observed developed other signs of lieart trouble, and drifted and died, others pursued healthy lives none the worse for the condition causing the irregular action. I endearoured to obtain the facts that would lead me to predict these different results, so that at the end of twenty five years I was able to give with some degree of confidence the grounds on which a prognosis should be based. It will be gathered that to attain this end a vast amount of work liad to be done, for to elucidate this one point I must have taken over 20,000 graphic records.

The importance and necessity for this work will bc appreciated when it is realized that this irregularity is of great frequency and may occur at all ages. The doctor is frequently consulted because the patient is conscious of its presence, and a great number of individuals are subjected to most elaborate and expensive treatment for it. Moreover, examiner's for life insurance and for entrance into the services frequently detert it, and hitherto there has been no guide as to its significance. Some reject candilates because of it, others pass them. In no place, neither in the teaching at the schools nor in the books dealing with this subject, is there any description of the principle that should guide the medical man in recognizing the significance of this simple sign.

I have been struck by the attitude of the ploysicians to work of this kind that I have undertaken. I have often met with cordial recognition of the worli I have done, but I do not remember seeing a single reference to this part of my work-the work that has caused the greatest amount of trouble, and which has been beset with the greatest difficulties, and which nevertheless has been of the greatest value. Rather have my views been the subject for depreciation, in the sense that my prognosis has been treated as of no account, for it was known to the profession long before I undertook the work.

Time and again I have been told by teachers of experience and by author's of textbooks, that all the statements I had made in regard to prognosis were well known long before my day. When I asked why they had not published this information-for in no book is there the slightest hint how to differentiate these irregularities the one from the other, let alone giving their prognostic significance-I have bcen informed that it was a matter of common knowledge, and it was not necessary to mention it !

So little do the scientific trained physicians of the present day realize the only method by which a prognosis should be arrived at, that I am continually meeting with instances when a confident prognosis is given in cases which the writer has only observed after a few montlis or a few year's, when I have been following similar cases for many years, and have yet failed to appreciate fully the prognostic significance of the symptoms.

Illestratroys of the Help towards Research that can be given by the General Practitioner.

If a survey be made of the progress of medicine during the last twenty years, there is one field that stands out prominently in which advance has been greater pro. bably than in any other corresponding field-namely, in the diseases of the heart. The advance that has been macle in that time constitutes a revolution. Signs and symptoms that a few years ago were looked upon as being inexplicable have been clearly differentiated, the mechanism of their production unravelled, their bearing on the heart's efficiency understood, their indications for treatment analysed, and their prognostic significance clearly defined. Syumptoms that were not even suspected to exist have been discovered, and their recognition has thrown a flood of light on many obscure actions of the hear't. In addition, for the first time the treatment of heart affections has been based on scientific principles, and the action of remedies has been studied with a degree of accuracy nerer attained in any other field of medicine. Moreover, these clinical researches have given a guide and an impetus to the study of the physiology of the heart by animal experiment which has revealed many new facts of the lighest importance.

The inception of all this work, the carrying out of the principal investigations, and the great bulk of the discoreries were due to general practitioners, unhelped by any of the hospital and laboratory contrivances which are considered essential to research. With a few exceptions teachers of medicine were oblivious of the fact that this great advance was taking place, and have failed to appreciate its significance.

\section{Conclesions}

From these considerations it will be seen that if clinical medicine is to advance, if it is ever to attain the dignity of a science, a new spirit must be infused into the teaching. Symptoms that have hitherto been ignored, and however insignificant they secm, must be systematically investigated to find out the mechanism of their production and their bearing on the patient's future.

The early stages of disease must be searched for more thoroughly, and in this respect the little explored field of subjective sensations must be systematically investigated in order to correlate them with disordered functions.

Prognosis must be worked out on definite scientific lines by the continuous observation of individual cases over many years.

Treatment must be rationalized and put on an exact basis by the acquisition of precise methods of observation and by instructing the students to study for themselves the effects of remedies on the human body.

The general practitioner must be recognized as an essential adjunct in research. To him especially we should look to find out the early stage of disease and its progress. Hitherto the lack of this assistance has been the cause of the tardy advance of medicine. How complete this failure to recognize his opportunities is seen in the attitude of the leaders of the profession. Not a single general practitioner, nor any one cognizant of his opportunities, was asked to give evidence before the Royal Commission on University Education in London. Though money in abundance is forthcoming for research no one ever dreams of giving financial help to the individual of all individuals that could undertake this work.

The following brief description indicates lines on which clinical medicine should be taugint so as to instruct students and to promote the investigation of disease :

Take a hospital which has 100 beds for teaching clinical medicine. For teaching purposes at least four teachers world be necessary. The larger proportion of these bedssay screnty-should be placed under the care of the two junior physicians. These beds would bo occupied by the type of patient that at present fills the hospital. In these wards the student would spend half his time allotted to clinical medicine, and would be taught the physical signs of disease, the mechanism of their production, their bearing on the future life of the patient, and the indications they give for treatment. The action of each remedy administered would be watched with particular care, so that the student, by personal observation, might pereeive the effects of remedies and acquire the knowledge how to determine the value of remedies. The post-mortem appearances of such patients as dieel should be studied, with particular reference to such physical signs as were present during life, so that the student, by direct 
observation, might appreciate the relation of the physical sign to the morbid condition causing it.

After learning to recognize the more obvious signs of tisease and the mechanism of their production the student would pass to the senior physician, who would hare charge of the out-paticnt department. Here the student would study the early stages of disease-stages before the appearance of definite physical signs directly due to the disease. The symptoms here are more elusire-sub. jective mainly, or shown only by otlier organs secondarily affectecl.

'The senior physicians only by their knowledge. acquired after long expericnce, are capable of duly appreciating and detecting these more subtle signs. To these physiciaus thirty beds would be allotted. A proportion of these beds would be used for the purpose of the more careful study of those cases the examination of which could not be com. pleted in the ont-patient department, and in which the assistance of accessory methods of diagnosis are required, as test meals, $x$-ray, blood, and bacteriological examinations, and cardiographic observations.

In the ont-patient department careful records of all patients, even with trivial signs, shonld be liept, and arrangements made by which these patients should be systematically watched for long periods of time. When they do not conre to the hospital, trained assistants, with istudents, should be told off to visit them at their homes, and reports should be made of the course of their complaint.

It is manifest that it is only by such mothods that the progress of discase can be detected in hospital patients, whilo assistant and student will get an insight into the manner in which discase presents itself for diagnosis and treatment in general practice.

'Teachers of clinical medicine should not be appointed until some ten ycar's after qualification. During that time they will have had an opportunity of showing that they are capable of invesstigating discase. One-half of the teacher's should have been en. gaged in general practice, while the others may have been engaged in laboratory work, with particular application to clinical investigation.

Each physician appointed should be expected to engage in some field of research, having particular reference to the more common forms of disease. As far as possible the subjects for investigation should not overlap, so that the student in passing through his curriculum should be brought into contact with the progress of medicine in as many different fields as possible. In this way the teaching will be more effective, for the teacher will be spealing from actual experience, and not be merely the monthpiece of tradition or hearsay, while the student, participating in his teacher's research, will have his interest quickencd and will learn how to investigate.

$A$ certain number of beds allotted to the physician can be reserved for the particular line of investigation in which he is engaged.

There should be a constant intercourse betreen the physician and the heads of other departments in the school, as the surgeon, bacteriologist, physiologist, experimental pharmacologist, in the investigation and treatrent of the patients.

THF Naharajah of Nepal has informed the Committec of Management of the Brompton Hospital that an anonymous donor is prepared to give $£ 1,300$ towards the endow. ment of the researeh work of the hospital. The hospital is appealing for a further sum of $£ 5,000$ for the purpose of maintaining and extending the research work, and the Maharajah, through whose munificence the hospital was cnabled two years ago to extend the existinis accommodation for such work, has expressed the hope that this new donation may serve as an incentive to others to come forward with a helping hand. The work is under the direction of Di. A. C. Inman, who informed a representative of the T'imes that one of the problems proposed to be attacked was the evolution of a test similar to the Wassermann reaction in syphilis, which would be of use in recognizing the presencc of the infection in early and latent stages.

\section{A FAMILY WITH CEREBELLAR A'TAXIA.}

\author{
$3 x^{\circ}$
}

C. A. SPRAWSON, M.D., M.R.C.P.LoNi, M.Jor I.Mi.S., PROFESSOR OF MEDICINE, KING GEORGI's MEDICAL COLLEGE, LUCKSOW.

A Eurasian male (E. S. P.), aged 35, came to the outpatient department of King George's Hospital, Luclinow complaining of tremors on standing and of giddiness. He resembled at first sight a case of disseminated sclejosis but examination showed points of difference; he was admitted to hospital. There is nothing of importance in the previous history. The history of his present illnes: was that three and a half year's ago he noticed that his head was often shaking. He continued in this condition for about a year, and then had an attack of intermittent fever, nature unlinown, lasting a month. After this his gait became more staggering and lie noticed gcneral tremors of the body and limbs; he suffered from giddiness and felt often that he was about to fall. He managed to continue at his work as a proof reacler for another two years, and then found his disease had adranced so far as to prevent him doing his work, and six months later ho came to the hospital. Inquiry elicited that other's of his family, including his father, had been and were similarly affected, and further investigation and examination of other members of the family has snceceded in producings the genealogy shown in the table.

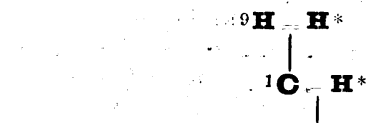

\section{.}

